\title{
PronombRes EN WAYUUNAIKI Y ESPAÑol: UNA MIRADA CONTRASTIVA
}

\author{
Pronouns in Wayuunaiki and Spanish: A Contrastive Analysis \\ Pronoms en Wayuunaiki ET EsPagnol : Une anAlyse contrastive \\ Pronomes em WayuUnaiki e espanhol: uma análise Contrastiva
}

\author{
Leonel Viloria Rodríguez \\ Candidato a magíster en Lingüística, \\ Universidad del Atlántico, \\ Barranquilla, Colombia. \\ leojovi@mail.uniatlantico.edu.co \\ https://orcid. \\ org/0000-0001-5615-8753
}

\author{
Johan De La Rosa Yacomelo \\ Profesor asistente, Universidad del \\ Norte, Barranquilla, Colombia. \\ iyacomelo@uninorte.edu.co \\ https://orcid. \\ org/0000-0003-1671-8431
}

\author{
Rudecindo Ramírez González \\ Profesor titular, Universidad de La \\ Guajira, Riohacha, Colombia. \\ rramirez@uniguajira.edu.co \\ https://orcid. \\ org/0000-0001-7115-0573
}

\author{
Daniela García Segura \\ Candidata a magíster en Lingüística, \\ Universidad del Atlántico, \\ Barranquilla, Colombia. \\ dgarciasegura@mail.uniatlantico. \\ edu.co \\ https://orcid. \\ org/0000-0002-8975-3070
}

\section{RESUMEN}

La literatura relacionada con estudios contrastivos entre lenguas nativas de Colombia y el español es muy escasa. En aras de contribuir al cambio de esta realidad, este estudio ofrece un análisis contrastivo de los pronombres de sujeto, objeto directo e indirecto entre las lenguas wayuunaiki y español. La comparación se enmarca en la lingüística contrastiva y da cuenta de las similitudes y diferencias entre los sistemas gramaticales de ambas lenguas. Los resultados ponen en evidencia algunas semejanzas entre las dos lenguas, como el uso de sujetos nulos y el hecho de que sus pronombres, con algunas excepciones de los de sujeto, no establecen diferencias entre géneros para la primera y la segunda persona, contrario a lo que sucede con la tercera. Por otro lado, también revelan algunas diferencias notables en relación con la posición que estas unidades gramaticales ocupan en la estructura oracional, las marcas utilizadas cuando no se enuncia explícitamente el pronombre de sujeto y la estructura morfológica. Este estudio constituye una primera mirada contrastiva y tiene implicaciones para la enseñanza de lenguas, la traducción, y los estudios de contacto de lenguas y de bilingüismo, dada la identificación que hace de posibles interferencias, variaciones y cambios lingüísticos.

Palabras clave: bilingüismo; enseñanza y aprendizaje de lenguas; español; lingüística contrastiva; pronombres; wayuunaiki.

\section{Abstract}

Contrastive studies between Colombian aboriginal languages and Spanish are scarce. To fill this gap, this study provides a contrastive analysis of the subject, direct object, and indirect object pronouns in both Wayuunaiki and Spanish. The comparison is part of contrastive linguistics and accounts for the similarities and differences between the grammatical systems of both languages. The results show

Recibido: 2021-05-13 / Aceptado: 2021-10-04 / Publicado: 2022-02-11

https://doi.org/10.17533/udea.ikala.v27n1a08

Editora: Doris Correa, Universidad de Antioquia, Medellín, Colombia.

Derechos patrimoniales, Universidad de Antioquia, 2022. Este es un artículo en acceso abierto, distribuido según los términos de la licencia Creative Commons BY-NC-SA 4.0 Internacional. 
some similarities between the two languages related to the use of null subjects and the fact that their pronouns, with some exceptions for the subject, do not establish differences between genders for the first and second person, contrary to what happens for the third. On the other hand, they also reveal some notable differences in relation to the position that these grammatical units occupy in the sentence structure, the marks used when the subject pronoun is not explicitly stated, and the morphological structure. This study constitutes a first contrastive look at both languages and has implications for language teaching, translation, language contact studies and bilingualism, given the identification it makes of possible interferences, variations and linguistic changes.

Keywords: bilingualism; language teaching and learning; Spanish; contrastive linguistics; pronouns; langue Wayuunaiki.

\section{RÉSUMÉ}

La littérature que s'occupe des études contrastives entre les langues indigènes en Colombie et la langue espagnole est insuffissante. Afin de rémédier ce manque, cette étude propose une analyse contrastive du sujet, des pronoms des objets directs et indirects entre les langues wayuunaiki et espagnole. La comparaison est encadrée dans la linguistique contrastive et rend compte des similitudes et des différences entre les systèmes grammaticaux des deux langues. Les résultats montrent quelques similitudes entre les deux langues, comme l'utilisation de sujets nuls et le fait que leurs pronoms, à quelques exceptions pour le sujet, n'établissent pas de différences entre les genres pour la première et la deuxième personne, contrairement à ce qui se passe avec le troisième. D'autre part, ils révèlent aussi quelques différences notables, comme la position qu'occupent ces unités grammaticales dans la structure de la phrase, dans les marques utilisées lorsque le pronom sujet n'est pas explicitement énoncé, et dans sa structure morphologique. Cette étude constitue un premier regard contrastif et nous espérons que ses résultats puissent être appliqués dans l'enseignement des langues, la traduction, les études de contact linguistique et de bilinguisme, à partir de l'identification des interférences possibles, ainsi que de la variation et des changements linguistiques.

Mots-clés : bilinguisme ; enseignement des langues ; espagnol ; linguistique contrastive; pronoms; Wayuunaiki language.

\section{RESUMO}

A literatura relacionada aos estudos contrastivos entre as línguas nativas da Colômbia e o espanhol é muito escassa. Com o objetivo de contribuir para mudar essa necessidade, este estudo oferece uma análise contrastiva sobre os pronomes de sujeito, e de objetos direto e indireto entre as línguas wayuunaiki e espanhola. A comparação é estruturada em linguística contrastiva e explica as semelhanças e diferenças entre os sistemas gramaticais de ambas as línguas. Os resultados mostram algumas semelhanças entre as duas línguas, como o uso de sujeitos nulos e o fato de seus pronomes, com algumas exceções para o sujeito, não estabelecerem diferenças entre os gêneros para a primeira e segunda pessoa, ao contrário do que ocorre com a terceira pessoa. Por outro lado, também revelam algumas diferenças notáveis, como a posição que essas unidades gramaticais ocupam na estrutura da frase, nos sinais usados quando o pronome sujeito não é explicitamente enunciado e na sua estrutura morfológica. Este estudo constitui uma primeira abordagem contrastiva e esperase que seus resultados possam ser aplicados no ensino de línguas, a tradução, os estudos de contato linguístico e o bilinguismo, a partir da identificação de 
possíveis interferências, bem como da variação e mudanças linguísticas.

Palavras chave: bilinguismo; ensino e aprendizagem de línguas; espanhol; linguística contrastiva; pronomes, língua Wayuunaiki. 


\section{Introducción}

El español y el wayuunaiki comparten espacio en La Guajira colombiana y en territorio venezolano. Ambas lenguas coexisten y comparten funciones en la sociedad guajira (véanse Etxebarria Arostegui, 2012; Mejía Rodríguez, 2011; Pérez van Leenden, 2003; R. Ramírez, 2011), en donde el número de hablantes bilingües se incrementa en la medida en que aumenta el flujo migratorio hacia las principales ciudades de habla hispana en la región. Por esto, se ha buscado preservar y promover la lengua indígena mediante procesos etnoeducativos e iniciativas comunitarias y gubernamentales. Ante tales proyectos, ha surgido un creciente interés por la publicación de materiales y la enseñanza de cursos en wayuunaiki en los últimos años (véase Anexo 1).

Frente a este panorama que promueve el aprendizaje y el uso de la lengua indígena, se hacen pertinentes los estudios contrastivos entre ambas lenguas, que permitan establecer las zonas en que sus gramáticas convergen y divergen. En esencia, identificar las áreas de divergencia permitirá focalizar la atención hacia dichos elementos gramaticales, esto teniendo en cuenta que lo diferente suele asociarse a error en el aprendizaje de la segunda lengua (L2) (Rienda y Nieto, 2018, p. 104). Este tipo de análisis contrastivo resulta muy útil para los estudios de contacto de lenguas, para la adquisición y la enseñanza del español y del wayuunaiki como L2, así como para la traducción y el diseño de materiales.

Uno de los puntos de divergencia entre los sistemas gramaticales de estos idiomas es el uso de los pronombres de sujeto, objeto directo y objeto indirecto. $\mathrm{Al}$ ser de diverso origen (el español es una lengua indoeuropea de tipo romance, del grupo ibérico; el wayuunaiki, una lengua arawak, de la rama septentrional o norteña; véase Aikhenvald, 1999), poseen muchas diferencias en cada uno de sus niveles. Sin embargo, también es posible encontrar similitudes.

Teniendo en cuenta lo anterior, el objetivo principal de este artículo es establecer una comparación pormenorizada del uso de estos pronombres en ambas lenguas. Esto, con el propósito de ponerla a disposición de la comunidad académica y despertar el interés en el desarrollo de análisis contrastivos entre lenguas indígenas con el español.

El análisis propuesto está organizado en los siguientes apartados: inicialmente, se ofrece una mirada sucinta sobre los fundamentos teóricos que guían el estudio. Luego, se detalla la metodología empleada en este trabajo. A continuación, se hace la comparación entre los pronombres personales de sujeto en las dos lenguas en contraste; de igual manera entre los pronombres que funcionan como objeto directo y los que fungen como objeto indirecto. Posteriormente, se aborda una discusión sobre la utilidad de esta comparación y las predicciones que se originan de dicho estudio. Por último, se plantean algunas conclusiones, implicaciones y posibles proyecciones derivadas de este trabajo.

\section{Marco teórico}

En este apartado se ofrece, en primer lugar, un acercamiento a cada una de las lenguas objeto de estudio y se esboza un contraste conciso entre las mismas, atendiendo a la tipología lingüística, a la historia y al estado actual de ambas. Además, se presenta una aproximación teórica a la categoría gramatical analizada y, en especial, a los pronombres personales, los cuales constituyen el principal objeto de análisis de esta investigación.

\section{Wayuunaiki y español: una mirada contrastiva}

El presente trabajo se enfoca en dos lenguas de distinta tipología lingüística e historia. El español es una lengua romance, perteneciente al grupo ibérico. De acuerdo con datos encontrados en Ethnologue (s. f. 1), el número de hablantes de este idioma, para el año 2019, era de 542894510 , los cuales se distribuyen en 471397370 hablantes como primera lengua (L1) y 71497140 como L2. Su uso se extiende a más de 21 países como idioma oficial. En el presente, este goza de un estatus privilegiado, hasta el punto de ser considerado la cuarta 
lengua más poderosa a nivel mundial (Instituto Cervantes, 2019). En Colombia, se ha fomentado como la lengua predominante desde el nacimiento de la república y a través de las constituciones políticas de 1886 y 1991 . Su prestigio a nivel nacional no es compartido con ninguna otra lengua, pues este tiene un "amplio uso en la sociedad nacional" (Trillos Amaya, 2020, p. 177); sin embargo, comparte estatus como lengua oficial con el wayuunaiki en el departamento de La Guajira.

Por su parte, el wayuunaiki posee el mayor número de hablantes entre todas las del tipo arawak (Landaburu, 2004-2005, p. 5). Según los datos reportados por Ethnologue (s. f. 2), hay alrededor de 416000 hablantes nativos en los dos países (122 000 en Colombia y 294000 en Venezuela). La misma fuente revela que su porcentaje de alfabetismo ronda entre el 5 y el $15 \%$ de la población. Los estudios sociolingüísticos sobre el wayuunaiki (p. ej. Etxebarria Arostegui, 2012; Mejía Rodríguez, 2011, Pérez van Leenden, 2003; R. Ramírez, 2011) revelan que el número de hablantes monolingües disminuye en la medida en que el español gana terreno.

Además de las diferencias de origen y distribución, existen otras a nivel interno del sistema lingüístico. Por ejemplo, el español posee un orden sintáctico flexible, en el cual el patrón predilecto es sujeto + verbo + objeto (svo), mientras que el wayuunaiki es de orden vso. Otra diferencia es que la primera se considera una lengua flexiva fusional (véanse Almela, 2015; Mijangos y Ponce de León, 2017), y la segunda, una lengua aglutinante (Pimiento Prieto y Pérez van-Leeden, 1997, p. 160). Además, los repertorios fonológicos son diferentes: el wayuunaiki posee 15 fonemas consonánticos y 12 vocálicos ( 6 vocales cortas y 6 largas), mientras que el español generalmente posee 18 consonánticos y 5 vocálicos (Salcedo, 2010). Ahora bien, las diferencias descritas no indican que no existan puntos en común entre el wayuunaiki y el español. En este sentido, los estudios contrastivos apenas comienzan a aflorar.
En este trabajo se muestran algunas similitudes y diferencias entre los sistemas pronominales de ambas lenguas, pero antes se presentan las bases teóricas del uso pronominal a nivel general.

\section{Pronombres personales}

Los pronombres personales son unidades o formas gramaticales que señalan a los interlocutores en cualquier acto de comunicación. Así, estas unidades o formas tienen una existencia común en todas las lenguas hasta la fecha estudiadas. De acuerdo con Fernández (1999), estos pronombres resultan polémicos al momento de proponerles una definición y clasificación gramatical. No obstante, el diccionario electrónico de la Real Academia Española (2019) los describe como palabras que "hacen las veces del sustantivo o del sintagma nominal y que se emplean para referirse a las personas, los animales o las cosas sin nombrarlos". Entre las características propias de estas unidades se encuentran: cumplir funciones sintácticas de sustantivo, carecer de contenido semántico y denotar inequívocamente (Fernández, 1999, p. 1211).

Este tipo de unidades gramaticales tienen por objeto referir a los participantes, sean protagonistas o no, del acto comunicativo (Gallardo, 2004; MorenoFernández et al., 2020). De acuerdo con la Nueva gramática de la lengua española (Real Academia Española, 2010; en adelante NGDLE), estos reciben dicha denominación dada su particularidad de presentar características gramaticales de persona. En palabras de Creissels (2006, p. 7), son un conjunto de expresiones que aluden a las entidades animadas participantes del proceso de comunicación y, por tanto, son susceptibles de ser representados por constituyentes nominales canónicos.

En este orden de ideas, el español y el wayuunaiki gozan de la presencia de los pronombres, los cuales cumplen distintas funciones en las construcciones oracionales (Álvarez, 2017; Mansen y Captain, 2000; Ramírez y Dieck, 2019; Real Academia Española, 2010). Entre las más comunes están: sustituir al grupo nominal de sujeto, al de objeto 
directo o al de objeto indirecto, y aparecer funcionando como pronombres oblicuos o pronombres posesivos. El presente análisis centra su interés exclusivamente en las tres primeras funciones referidas: pronombres de sujeto, pronombres de objeto directo y pronombres de objeto indirecto. Lo anterior, puesto que, podría decirse, son las de mayor uso en los actos comunicativos cotidianos.

Los pronombres personales pueden aparecer de forma expresa o nula, y existe variación en cuanto al uso de estas formas en todas las lenguas (véase, p. ej., De La Rosa Yacomelo, 2020a). En el caso específico del español, este es reconocido como lengua de sujeto nulo (o Pro-drop), lo cual permite identificar al referente por medio de la flexión verbal o del contexto. Aunque se han reportado diferencias dialectales en cuanto a los porcentajes de expresión de sujeto en el español, el Caribe es el lugar en el que más altos números de sujetos expresos se han encontrado (p. ej. Alfaraz, 2015; De La Rosa Yacomelo, 2020b; Holmquist, 2012; Martínez-Sanz, 2011; Orozco, 2015; Otheguy y Zentella, 2012). El wayuunaiki, por su parte, permite la identificación del referente a través de formas libres (pronombres independientes) o de formas ligadas al verbo (véanse, p. ej., Ramírez y Dieck, 2019, y Sabogal Valencia, 2018), aunque también se reconocen formas clíticas y nulas (Ramírez y Dieck, 2019).

En cuanto al contacto entre el español hablado en La Guajira y el wayuunaiki, debe anotarse que son pocos los estudios enfocados en ello, y solo en los últimos años se ha comenzado a apreciar un interés creciente en el tema. Hasta el momento se ha documentado que el primero se destaca por una mayor tasa de pronombres abiertos en hablantes bilingües y monolingües (Méndez, 2020), lo que está en consonancia con el español del Caribe, sin una diferencia notable entre ambos grupos. De igual manera, este se caracteriza por desviaciones en la conjugación de verbos por parte de los bilingües, quienes adoptan la conjugación de la 3 . $^{\text {a }}$ persona singular por defecto (p. ej. "Yo sabe leer"; Méndez, 2020, pp. 115, 139).
Además de lo anterior, se han reportado inconcordancias de género y de número, omisión de verbos copulativos, uso desviado de preposiciones (p. ej. “...o sea la puerta de la, donde [Ø] máquina, se abrió así...," "Mi mamá tuvo nueves hijos., "Estoy pensando de no tener porque no dicen uno", H. Ramírez, 2012, pp. 674-681; véase también Atencio, 2014), masculinización y feminización anómala de sustantivos, además de velarización de nasales en posición nuclear (p. ej. "serrucha" por "serrucho" y [mankï] por /mango/; en Oquendo, 2014, p. 150). De igual modo, se han identificado muchos préstamos lexicales y cambios de códigos en ambas lenguas (p. ej. "Küwernasion" para "Gobernación”, y el cambio de código "Sü-pensajü-in Aana Antonio" "Ana pensó en Antonio"; Ramírez González y De La Rosa Yacomelo, 2021, pp. 11-13). A pesar de estos hallazgos, puede afirmarse que, por el momento, son más las inquietudes que las certezas sobre el español hablado en la zona y la influencia de este en la lengua indígena.

\section{Método}

Con el fin de establecer semejanzas y diferencias entre la configuración y el uso de los sistemas pronominales en español y wayuunaiki, el presente trabajo se enmarca en la lingüistica contrastiva. Esta constituye una rama de la lingüística general que pretende "la identificación de las diferencias y similitudes existentes, de forma sincrónica, entre dos, o más lenguas, sean estos elementos lingüísticos o socioculturales" (Rienda y Nieto, 2018, p. 104). $\mathrm{El}$ aporte del método comparativo promovido por esta rama de la lingüística ha sido de mucha utilidad para contribuir a la enseñanza y el aprendizaje de lenguas, así como a los estudios de traducción (Ramón García, 2001; Tricás Preckler, 2010).

La comparación desarrollada en el presente trabajo se realizó a partir de dos referentes principales, uno para cada idioma. Para el wayuunaiki, se tomó el estudio de Ramírez y Dieck (2019), una investigación detallada de los pronombres personales en la lengua wayuu. En esta se brinda una mirada actual y complementaria a otros trabajos 
que se habían realizado sobre el tema en cuestión (p. ej. De Carvalho, 2016; Ehrman, 1972; Olza y Jusayú, 2012), aunque no desde un punto de vista comparativo. Para el español, se utilizó la NGDLE (Real Academia Española, 2010), el último referente gramatical publicado por la Real Academia Española, y, por tanto, quizás, el más completo y actualizado en lo que concierne a este idioma.

Es necesario señalar que, dado que en español se ha comprobado la existencia de distintos sistemas pronominales (Fernández-Ordoñez, 1994; Fontanella de Weinberg, 1999), en este trabajo se utiliza el sistema denominado "etimológico" o "sistema de caso", esto por cuanto es el predominante en la región en que el español y el wayuunaiki están en contacto. El uso de los dos referentes antes enunciados, sumado a otros (citados en las referencias), permitió una mirada holística y rigurosa en la elaboración del presente estudio.

Con el fin de facilitar la comparación, se abordaron, en su respectivo orden, tres tipos de pronombres (de sujeto, de objeto directo y de objeto indirecto). Para cada tipo, se presentan tablas comparativas, con información acerca de cómo la persona gramatical, el género y el número del referente incide en su realización en wayuunaiki y español. Además, se brinda información sobre las configuraciones de uso de los pronombres de acuerdo con otros elementos sintácticos (p. ej. orden oracional o transitividad). En la siguiente sección, se observan los detalles mencionados.

\section{Resultados}

El trabajo realizado evidenció que, entre el español y el wayuunaiki, existen diferencias y semejanzas importantes en los tipos de pronombres analizados. En este apartado se presenta, de manera didáctica, en primer lugar, la comparación entre los pronombres de sujeto. Luego, se expone el contraste entre los pronombres de objeto directo y, por último, se hace lo mismo con los pronombres de objeto indirecto.

\section{Contraste entre los pronombres de sujeto}

Los pronombres personales de sujeto, tanto en español como en wayuunaiki, cumplen la función de sustituir o constituir el sintagma nominal de la oración (Álvarez, 2017; Mansen y Captain, 2000; Ramírez y Dieck, 2019; Real Academia Española, 2010).

Resulta importante destacar que, en wayuunaiki y en español, este tipo de pronombres guardan similitudes. Una de ellas consiste en que, en ambas lenguas, aparecen como morfemas libres, es decir, pueden constituir por sí mismos un enunciado. Otra similitud es que sus formas libres son utilizadas tanto para oraciones transitivas como para las intransitivas en las dos lenguas. Asimismo, estos pronombres comparten el hecho de que no necesitan aparecer explícitos en las construcciones oracionales, pero ello implica el uso de marcas de persona que, en el caso del wayuunaiki, varían dependiendo de si el verbo es transitivo o intransitivo, lo cual se explica pormenorizadamente más adelante.

La Tabla 1 esquematiza en detalle estos pronombres en español y en wayuunaiki, teniendo en cuenta la persona gramatical $\left(1 .{ }^{a}, 2{ }^{a}\right.$ y $\left.3{ }^{a}\right)$, el número (singular o plural) y el género (masculino o femenino). Para mayor claridad, es necesario advertir que el género se ha subdividido para todas las personas gramaticales, pero no todas tienen dicha subdivisión en ambos sistemas lingüísticos. Entonces, cuando en el espacio de un pronombre, en cualquiera de los idiomas, no se realiza la división de las filas que corresponden al género, es porque este puede usarse tanto para masculino como para femenino (p. ej. la segunda persona singular en el español y la segunda persona plural en wayuunaiki). De igual manera, se proporcionan algunos ejemplos que muestran la forma cómo aparecen los pronombres referidos en la construcción oracional. En el Anexo 2 se presenta el sistema de abreviaturas utilizado en las tablas. 
El análisis de los ejemplos propuestos en la Tabla 1 permite observar algunas de las similitudes mencionadas anteriormente y, asimismo, las diferencias en las estructuras oracionales canónicas en cada lengua.

En el español, como ya se indicó, se puede apreciar que la estructura para oraciones afirmativas se organizaría así: sujeto (remplazado por el pronombre personal) + verbo + objeto. En wayuunaiki, la estructura oracional afirmativa resulta distinta al español: verbo + sujeto (remplazado en este caso por el pronombre) + objeto.

Respecto a estas dos estructuras, debe puntualizarse que, en español, contrario al wayuunaiki, hay flexibilidad en el orden oracional (p. ej. Yo vi a Luisa, a Luisa vi yo, vi yo a Luisa). Asimismo, debe resaltarse que al verbo en wayuunaiki se sufijan algunas

Tabla 1 Pronombres de sujeto en español y wayuunaiki

\begin{tabular}{|c|c|c|c|c|}
\hline $\begin{array}{l}\text { Persona } \\
\text { gramatical }\end{array}$ & Número & Género & Español & Wayuunaiki \\
\hline \multirow{14}{*}{ 1. ${ }^{a}$ persona } & \multirow{8}{*}{ Singular } & \multirow{5}{*}{ Masculino } & & Taya \\
\hline & & & & Ojït-ij-shi taya \\
\hline & & & & caer-PAS-MASC.SG ISG \\
\hline & & & $Y_{0}$ & ‘yo (hombre) me caí' \\
\hline & & & \multirow[t]{3}{*}{ Yo gané la carrera } & Taya \\
\hline & & \multirow{3}{*}{ Femenino } & & awat-aa-sï taya \\
\hline & & & & correr-PRES-FEM.SG ISG \\
\hline & & & & 'yo (mujer) corro' \\
\hline & \multirow{6}{*}{ Plural } & & Nosotros & \multirow{6}{*}{$\begin{array}{l}\text { Waya } \\
\text { o'ün-ü-shii waya } \\
\text { ir-PAS-PL 1PL } \\
\text { 'nosotros/as nos vamos' }\end{array}$} \\
\hline & & Masculino & Nosotros compramos ese & \\
\hline & & & auto & \\
\hline & & & Nesatras & \\
\hline & & Fomenino & 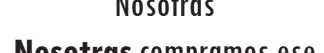 & \\
\hline & & rementino & auto & \\
\hline \multirow{16}{*}{ 2. ${ }^{a}$ persona } & \multirow{8}{*}{ Singular } & \multirow{5}{*}{ Masculino } & & Pia \\
\hline & & & Tú & 0'00j-ï-shi pia \\
\hline & & & Tú lloras todo el día & bañar-PAS-MASC.SG 2SG \\
\hline & & & Vos & 'tú (hombre) te bañaste' \\
\hline & & & Vos llorás todo el día & Pia \\
\hline & & \multirow{3}{*}{ Femenino } & Usted & Ayapïj-ï-sï pia \\
\hline & & & \multirow[t]{2}{*}{ Usted logrará la victoria } & Cocer-PAS-FEM.SG 2 SG \\
\hline & & & & 'tú (mujer) cosiste' \\
\hline & \multirow{8}{*}{ Plural } & \multirow{3}{*}{ Masculino } & Vosotros & \multirow{3}{*}{$\begin{array}{l}\text { akamaj-ï-shii jia } \\
\text { fumar-PAS-PL 2PL }\end{array}$} \\
\hline & & & Vosotros compráis ese & \\
\hline & & & auto & \\
\hline & & Femenino & Vosotras & 'ustedes (hombres/mujeres) fumaron' \\
\hline & & & Vosotras compráis ese & \\
\hline & & & auto & awalaj-ij-shii jia waima neer \\
\hline & & Neutro & Ustedes & pagar-PAS-PL 2PL mucho dinero \\
\hline & & & $\begin{array}{l}\text { Ustedes lograrán la } \\
\text { victoria }\end{array}$ & $\begin{array}{l}\text { 'ustedes (hombres/mujeres) pagaron mucho } \\
\text { dinero' }\end{array}$ \\
\hline
\end{tabular}


Tabla 1 Pronombres de sujeto en español y wayuunaiki (Cont.)

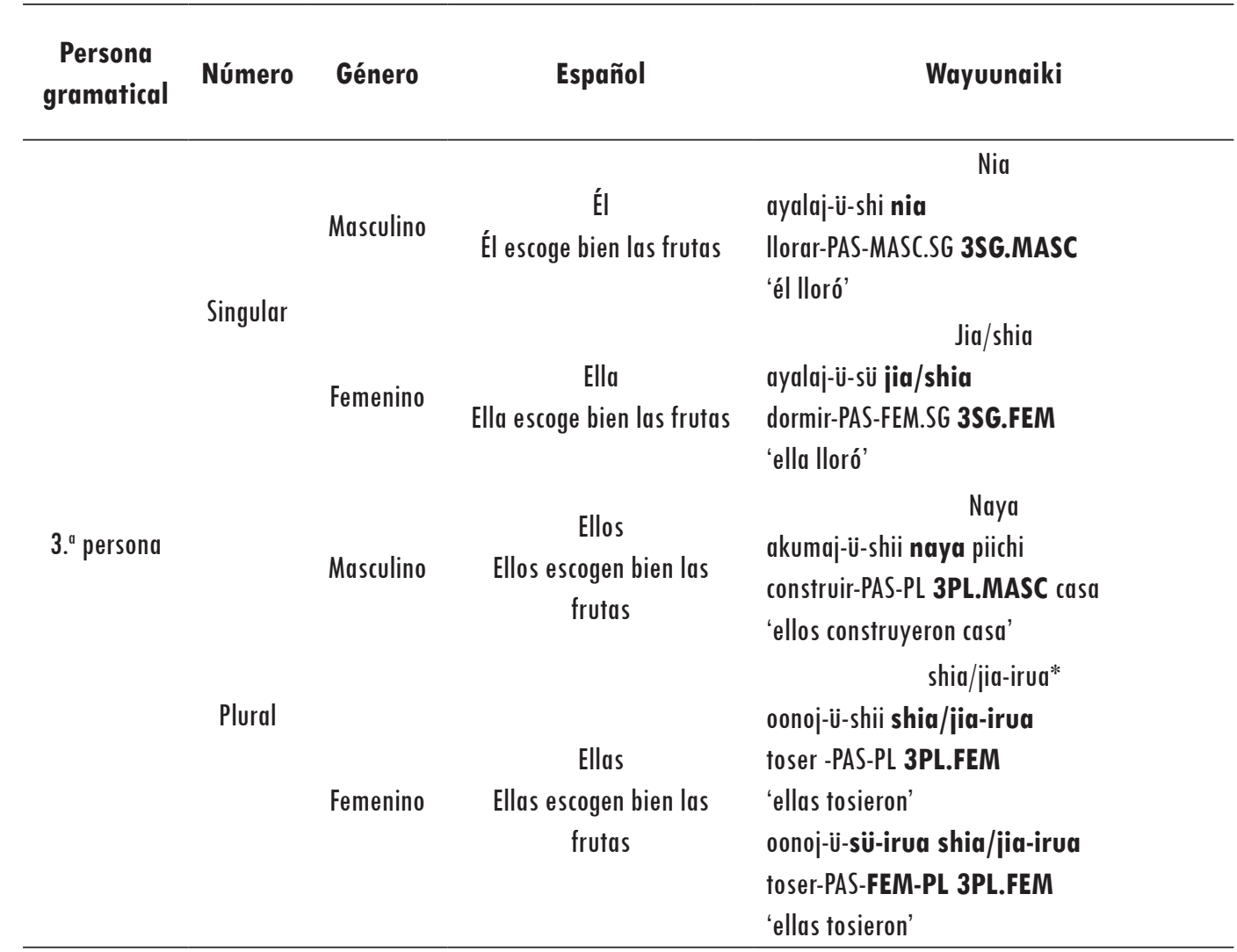

* Nótese que existen dos marcas para el femenino plural de tercera persona: -shii y -sü -irua. Asimismo, obsérvese que las formas jia o shia son diferentes realizaciones de la 3SG.FEM y la 3.FEM-PL, que dependen de la variedad regional hablada: en la Alta Guajira se usa jia; en la Media y Baja, shia (Ramírez y Dieck, 2019).

marcas de tiempo y de persona cuando aparece explícitamente el pronombre personal de sujeto, mientras que en español se sufijan marcas indistintamente de ello.

De lo anterior, se desprende una diferencia fundamental entre el español y el wayuunaiki: la posición que ocupa el pronombre personal de sujeto en la estructura oracional. En la lengua española, ocupa principalmente (no únicamente) la posición que precede al verbo; en wayuunaiki, ocupa la posición posterior al verbo. Estas posiciones aplican tanto para oraciones transitivas como para oraciones intransitivas cuando se realiza explícitamente el pronombre referido.

Ahora bien, resulta necesario anotar que, en ambas lenguas, entre el pronombre y el verbo pueden aparecer modificadores (aunque no es una posición habitual en español), como se ilustra en los Ejemplos 1 y 2.

$$
\begin{aligned}
& \text { Ejemplo 1: } \\
& \text { o'otoi-ee-chi joolu' taya ni-áu ta-ama-in } \\
& \text { montar-FUT-MASC.SG ahora 1SG } \\
& \text { SUP 1SG-caballo-GEN } \\
& \text { 'yo voy a montar ahora en mi caballo' } \\
& \text { Dieck, 2019, p. 492). } \\
& \text { Ejemplo 2: } \\
& \text { Ellos mañana asistirán a la fiesta. }
\end{aligned}
$$$$
\text { montar-FUT-MASC.SG ahora 1SG 3SG.MASC- }
$$$$
\text { 'yo voy a montar ahora en mi caballo' (Ramírez y }
$$

Otra diferencia importante radica en la forma de marcar el género y el número en estos pronombres. Como puede apreciarse en los ejemplos de la Tabla 1, en español, los pronombres de sujeto de primera y segunda persona de singular no 
establecen ningún mecanismo de diferenciación del género (generalmente hay elementos extralingüísticos que permiten reconocerlo). Por el contrario, el wayuunaiki sí establece esta diferencia en dichos pronombres, con una marca de género y número sufijada al verbo: - shi para el masculino singular y $-s \ddot{u}$ para el femenino singular (tanto en presente como en pasado). Caso contrario ocurre con los pronombres de primera y segunda persona plural, en los cuales el español establece una marca de género en el mismo pronombre (nosotros vs. nosotras y vosotros vs. vosotras), mientras que el wayuunaiki no lo hace (véanse ejemplos de la $1 .^{a} \mathrm{y}$ 2. ${ }^{a}$ persona plural en la Tabla 1 ). En relación con la tercera persona, ambas lenguas poseen pronombres diferentes para masculino y femenino, tanto en singular como en plural.

Las marcas de sujeto y número, sean ligadas al verbo o manifiestas en el pronombre, son propias de las dos lenguas. Sin embargo, existe una diferencia importante a establecer: en español, estas marcas no varían de acuerdo con el tiempo de la oración (ellos -escribieron, escriben, escribirán- una carta), mientras que en wayuunaiki sí se da dicha variación. Según lo expuesto por Ramírez y Dieck (2019), en wayuunaiki, con la marca de pasado - ü y la de presente $-a a$, se usa $-s h i$ para el masculino singular y $-s \ddot{u}$ para el femenino singular, así como -shii y -sü-irua para el masculino y femenino plural respectivamente. Siguiendo a los referidos autores, "con la marca de futuro $e e$ - aparecen las marcas - chi y - rü para el singular masculino y femenino respectivamente" (p. 497). Para el futuro plural se utiliza -shii cuando la oración es transitiva y $-n \ddot{u}$ cuando es intransitiva, esto independientemente del género.

Otros datos que resultan necesarios destacar son los siguientes: respecto a la segunda persona, el wayuunaiki no establece la diferencia entre un trato formal e informal (Mansen y Captain, 2000, p. 798), aspecto que sí se establece, principalmente, en el español de América. Por otro lado, debe señalarse que el pronombre de tercera persona femenina singular en la lengua wayuunaiki presenta variación dialectal: "en la Alta Guajira se usa jia, en la Media y Baja shia" (Ramírez y Dieck, 2019, p. 488).

Ahora, resulta necesario diferenciar las formas libres de los pronombres personales de sujeto (ejemplificadas en la Tabla 1) de las marcas de persona en las oraciones sin sujeto expreso: las dos lenguas poseen formas diferentes para marcar la persona en la estructura oracional con sujeto nulo (o cero). En el caso del wayuunaiki, cuando no aparece explícitamente el pronombre de sujeto en la oración, la forma de reconocerlo varía atendiendo a si esta es transitiva o intransitiva. En las oraciones intransitivas, simplemente no aparece el pronombre de sujeto y este puede inferirse a partir de la marca de persona y número sufijada al verbo (como se explicó anteriormente) y por el contexto oracional (véase el Ejemplo 3). Por el contrario, en las oraciones transitivas se utilizan marcas de persona prefijadas al verbo, como se ilustra en la Tabla 2.

Ejemplo 3:

atunk-ü-shi arika-müin

— dormir-PAS-MASC.SG ayer-DAT

‘(él) durmió ayer' (Ramírez y Dieck, 2019, p. 493).

Entonces, considerando la información de la Tabla 2 y lo expuesto en los párrafos precedentes a esta, en wayuunaiki, cuando no se realiza explícitamente el pronombre de sujeto, debe tenerse en cuenta la transitividad o intransitividad de la oración. Esto con el fin de determinar si se utilizan marcas prefijadas al verbo (como las indicadas en la Tabla 2) o sufijadas a este (como las utilizadas en la Tabla 1).

En la lengua española, contrario al wayuunaiki, la marca de persona y número, cuando no aparece explícito el pronombre de sujeto, no depende de la transitividad de la oración, es decir, no varía en atención a si la oración es transitiva o intransitiva. Además, estas marcas no se prefijan, sino que aparecen sufijadas al verbo, y varían dependiendo de la persona gramatical, del tiempo y del modo 
Tabla 2 Marcas de persona prefijadas al verbo para oraciones transitivas de sujeto nulo en wayuunaiki

\begin{tabular}{|c|c|c|c|c|}
\hline $\begin{array}{c}\text { Persona } \\
\text { gramatical }\end{array}$ & & Número & Marca & Ejemplo \\
\hline \multirow{6}{*}{ 1. persona } & \multirow{3}{*}{\multicolumn{2}{|c|}{ Singular }} & & ta-ayalaj-i-in wanee waireya-irua \\
\hline & & & ta- & 1SG-comprar-PAS-OD INDEF guaireña-PL \\
\hline & & & & 'yo compré unas guaireñas' (guaireñas = sandalias) \\
\hline & \multirow{3}{*}{\multicolumn{2}{|c|}{ Plural }} & & wa-ayalaj-ij-in wanee waireya-irua \\
\hline & & & wa- & 1PL-comprar-PAS-OD INDEF guaireña-PL \\
\hline & & & & 'nosotros compramos unas guaireñas' \\
\hline \multirow{6}{*}{ 2. ${ }^{a}$ persona* } & \multirow{3}{*}{\multicolumn{2}{|c|}{ Singular }} & & pi-ayalaja-ij-in wanee waireya-irua \\
\hline & & & $\mathrm{pij}-/ \mathrm{pi}-$ & 2SG-comprar-PAS-OD INDEF guaireñas \\
\hline & & & & 'tú compraste unas guaireñas' \\
\hline & \multirow{3}{*}{\multicolumn{2}{|c|}{ Plural }} & & ji-ayalaj-ï-in wanee waireya-irua \\
\hline & & & $\mathrm{ji}-/ \mathrm{ji}-$ & 2PL-comprar-PAS-OD INDEF guaireña-PL \\
\hline & & & & ‘ustedes compraron unas guaireñas' \\
\hline \multirow{12}{*}{ 3. " persona* } & \multirow{6}{*}{ Singular } & \multirow{3}{*}{ Masculino } & \multirow{3}{*}{$n \mathrm{ni}-/ \mathrm{ni}-$} & nï-kachej-ï-in wanee kuluulu-irua \\
\hline & & & & 3SG.MASC-colgar-PAS-OD INDEF tela-PL \\
\hline & & & & ‘él colgó unas telas’ \\
\hline & & \multirow{4}{*}{ Femenino } & \multirow{3}{*}{$\mathrm{jij}-/ \mathrm{ii}-$} & ji-ek-ï-in tï mansana-ka- $t$ \\
\hline & & & & 3SG.FEM-comer-PAS-OD DEF.FEM.SG manzana-DEF-FEM.SG \\
\hline & & & & ‘ella se comió la manzana' \\
\hline & \multirow{6}{*}{ Plural } & & \multirow{3}{*}{ na- } & na-ayalaj-ï-in wanee waireya-irua \\
\hline & & \multirow[t]{3}{*}{ Masculino } & & 3PL.MASC-comprar-PAS-OD INDEF guaireña-PL \\
\hline & & & & ‘ellos compraron unas guaireñas' \\
\hline & & & \multirow{3}{*}{ jia-irua- } & jia-irua-ayalaj-ì-in wanee waireya-irua \\
\hline & & \multirow[t]{2}{*}{ Femenino } & & 3PL.FEM-comprar-PAS-OD INDEF guaireña-PL \\
\hline & & & & ‘ellas compraron unas guaireñas' \\
\hline
\end{tabular}

*De acuerdo con Ramírez y Dieck (2019), "la variación entre jü-/ji-, nü-/ni-y pü-/pi- probablemente esté relacionada con la armonía vocálica. Sin embargo, por el momento, con los datos existentes, no se pueden postular regularidades concluyentes" (p. 495).

Fuente: Los ejemplos mostrados en esta tabla fueron tomados o adaptados del artículo "Los pronombres personales en wayuunaiki” (Ramírez y Dieck, 2019, pp. 493-494).

verbal. La Tabla 3 ilustra el uso de dichas marcas y proporciona ejemplos, con el fin de hacer más comprensible la manera en que aparecen y la posición que ocupan. Resulta imprescindible también tener en cuenta que, de acuerdo con la NGDLE (Real Academia Española, 2010), en ocasiones estas marcas pueden ser nulas (representadas con Ø).

Como puede advertirse en la Tabla 3, el esquema de marcación resulta algo complejo, más teniendo en cuenta que posibilita la generación de confusiones entre la marca para el pronombre de segunda persona singular (usted) y plural (ustedes), y los de tercera persona singular y plural, respectivamente. No obstante, deben disiparse a partir del contexto situacional en el acto de comunicación.

Las anteriores son las principales semejanzas y diferencias entre los pronombres de sujeto en las dos lenguas objeto del presente análisis. En el siguiente apartado, se establece la comparación entre los pronombres de objeto directo. 
Tabla 3 Marcas de persona sufijadas al verbo para oraciones de sujeto cero en español

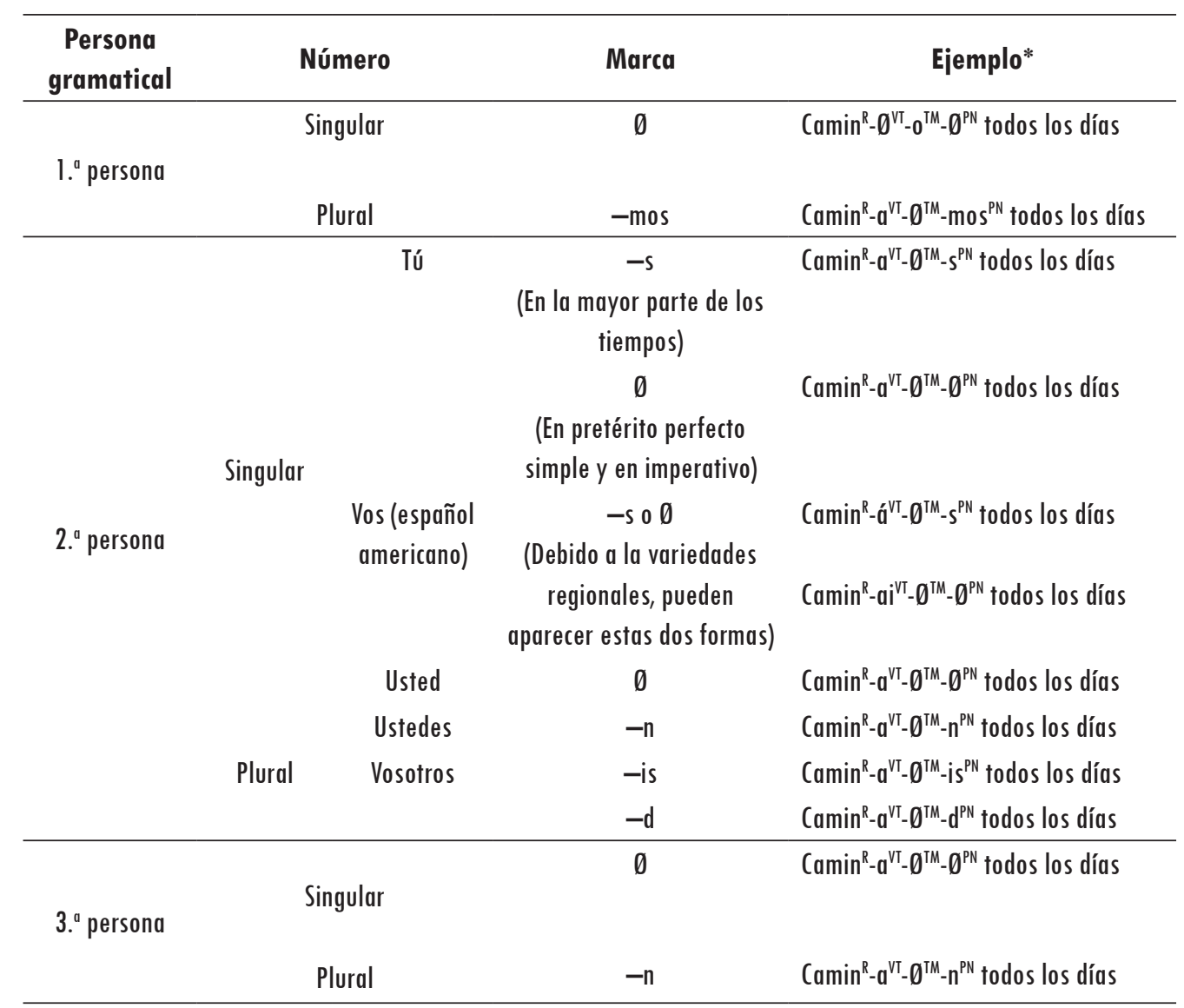

${ }^{* \mathrm{R}}$ (Radical), ${ }^{\mathrm{VT}}$ (Vocal temática), ${ }^{\mathrm{TM}}$ (Tiempo y modo), ${ }^{\mathrm{PN}}$ (Persona y número).

Fuente: Esta información fue obtenida y adaptada de la ngdle (Real Academia Española, 2010).

\section{Contraste entre pronombres} de objeto directo

Las formas para los pronombres personales de objeto directo en el wayuunaiki son las mismas que las formas libres de los pronombres de sujeto (Álvarez, 2017; Mansen y Captain, 2000; Ramírez y Dieck, 2019). Por el contrario, en la lengua española, las formas de estos pronombres varían en su totalidad. En la Tabla 4 se muestran las formas de los pronombres de objeto directo en español y en wayuunaiki, y se ilustran sus usos, así como algunas posiciones en las que pueden aparecer canónicamente.

La posición que ocupan estos pronombres en el plano oracional es nuevamente un punto de divergencia entre el wayuunaiki y el español. En la lengua española, los pronombres personales de objeto directo son clíticos y pueden aparecer en una posición proclítica o enclítica dependiendo del verbo, del tiempo y de la persona gramatical, como puede evidenciarse en los ejemplos de la Tabla 4. En este sentido, la estructura oracional canónica en que aparecen estos pronombres puede ser:

sujeto (en los ejemplos de la Tabla 4 se utiliza el sujeto cero o nulo) + pronombre personal de objeto directo + verbo + complemento circunstancial.

Por su parte, estos pronombres en la lengua wayuunaiki pueden ocupar distintas posiciones, 
Tabla 4 Formas de los pronombres personales de objeto directo en español y wayuunaiki

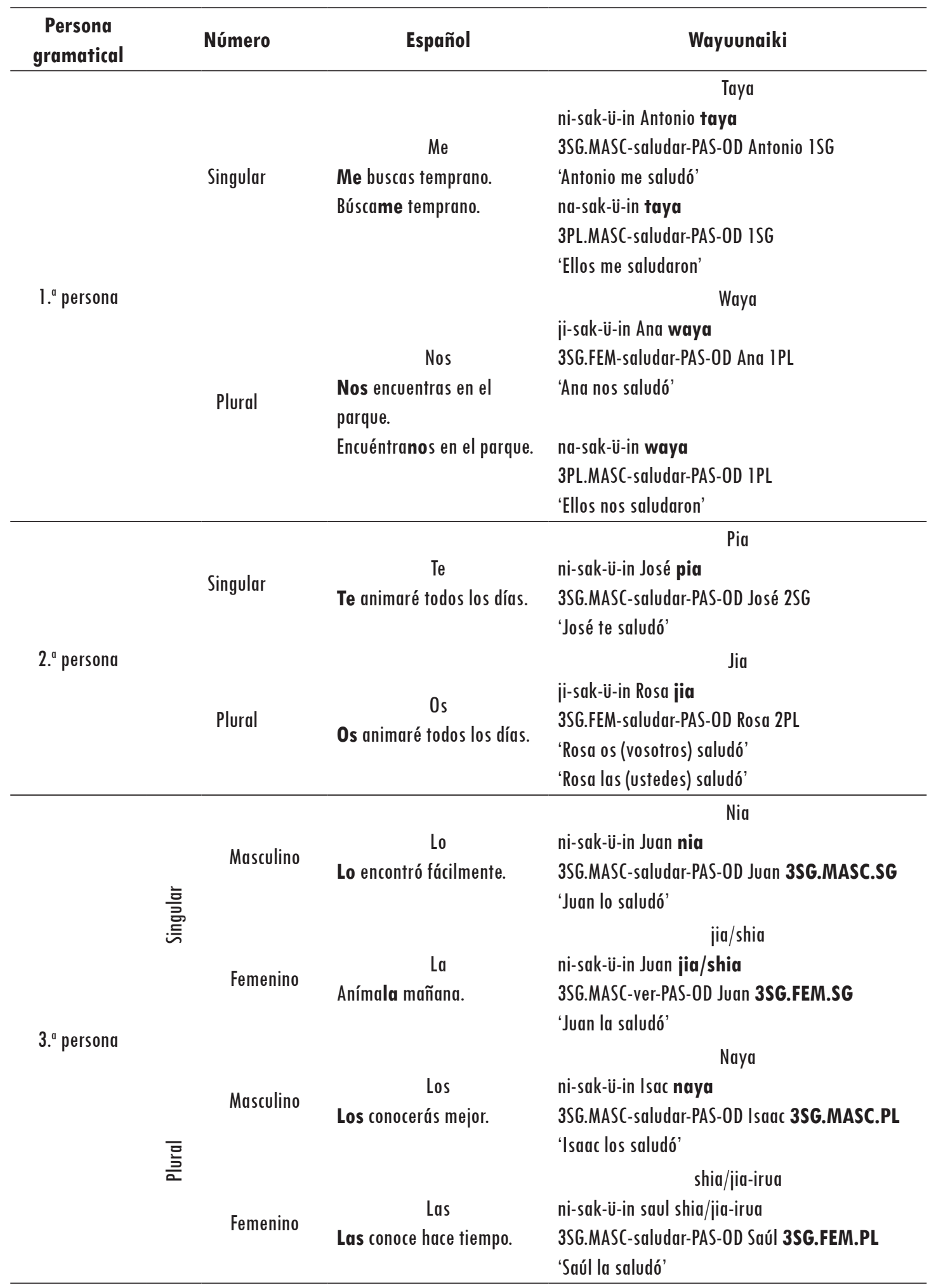

* Recuérdese que el contraste se ha realizado atendiendo el sistema pronominal “etimológico” del español. 
pero no parecidas a las del español, puesto que no aparecen nunca sufijados al verbo o antes del verbo. La posición en que se utilizan, como muestran los ejemplos de la Tabla 4, es posterior al sujeto en caso de que este aparezca lexicalmente (verbo + sujeto léxico + pronombre personal de objeto directo) o posterior al verbo en caso de que no se exprese explícitamente el sujeto (verbo + pronombre personal de objeto directo). Estos pronombres también pueden aparecer opcionalmente entre el verbo y el sujeto oracional léxico, pero en dicho contexto tienen el propósito de enfatizar, como se muestra en el Ejemplo 4.

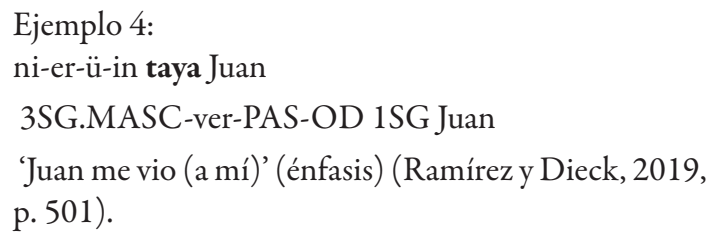

Un aspecto importante que no se debe pasar por alto es el hecho de que el español, en contraste con el wayuunaiki, tiene dos tipos de pronombres personales de objeto directo: los átonos, explicados en la tabla anterior, y los tónicos. Estos últimos están constituidos por los pronombres: mi, ti, vos, usted, él, ella, nosotros, nosotras, vosotros, vosotras, ustedes, ellos, ellas, sí.

Dos son sus características fundamentales, cuando funcionan como pronombres personales de objeto directo: coaparecen obligatoriamente con un pronombre átono y deben ser introducidos por la preposición a. Estos cumplen con la función de focalizar al referente sobre el que recae la acción del verbo y de diferenciarlo de otras posibles personas. En los Ejemplos 5 y 6 se ilustra su uso, tomando como referencia algunas de las oraciones de la Tabla 4.

Ejemplo 5:

Me buscas a mí temprano

Ejemplo 6:

Anímala a ella todos los días.

\section{Contraste entre pronombres de objeto indirecto}

En la lengua española, los pronombres personales de objeto indirecto mantienen las mismas formas que los pronombres de objeto directo para la primera y la segunda persona, tanto en singular como en plural. Esta situación podría prestarse para interpretaciones erróneas, pero estas se resuelven atendiendo a la aparición de otros morfemas o unidades lexicales que cumplan función de objeto directo, como puede apreciarse en la Tabla 5. El wayuunaiki, por el contrario, utiliza la marca de persona prefijada al verbo en las oraciones transitivas que no llevan el pronombre de sujeto explícito y se liga a dicha marca el morfema - müin (p. ej. tamüin), el cual indica la función de objeto indirecto (Ramírez y Dieck, 2019, p. 501). En la Tabla 5 se ilustra el uso de estos pronombres en las dos lenguas.

La Tabla 5 ilustra en detalle las distintas posiciones que puede ocupar el pronombre personal de objeto indirecto en las dos lenguas. En cuanto a la posición, en wayuunaiki, siguiendo a Ramírez y Dieck (2019), "el pronombre personal marcado para dativo puede variar: esta unidad puede aparecer antes del sujeto, después del sujeto o después del objeto directo” (p. 502). Así, su estructura sería:

verbo $+(\mathrm{P}$ objeto indirecto $)+$ sujeto $(\mathrm{P}$ objeto indirecto $)$ o verbo $+($ P objeto indirecto $)+$ sujeto + objeto directo + (P objeto indirecto).

En español, estos pronombres también pueden ocupar posiciones distintas en la estructura oracional. Los ejemplos de la primera persona singular lo ilustran perfectamente: en el primero, ocupa una posición proclítica; en el segundo, precede al pronombre de objeto directo proclítico, y en el tercero, aparece en posición enclítica ligada a la raíz del verbo (siempre antecediendo al pronombre de objeto directo enclítico en caso de que lo haya). Debe añadirse, además, que en español, los pronombres tónicos tratados en el apartado anterior 
Tabla 5 Formas de los pronombres personales de objeto indirecto en español y wayuunaiki

\begin{tabular}{|c|c|c|c|c|}
\hline $\begin{array}{c}\text { Persona } \\
\text { gramatical }\end{array}$ & & úmero/Género & Español & Wayuunaiki* \\
\hline \multirow[t]{14}{*}{ 1. persona } & \multirow{10}{*}{\multicolumn{2}{|c|}{ Singular }} & $\mathrm{Me}$ & ta-müin \\
\hline & & & Me compras un auto lujoso. & ¡̈̈-apaj-ï-in ta-müin Griselda wanee amüchi \\
\hline & & & Cómprame un auto lujoso. & 3FEM.SG-dar-PAS-OD ISG-DAT Griselda INDEF múcura \\
\hline & & & Me lo compras. & 'Griselda me dio una múcura' \\
\hline & & & Cómpramelo. & jï-apaj-ï-in Griselda ta-müin wanee amüchi \\
\hline & & & & 3FEM.SG-dar-PAS-OD Griselda 1SG-DAT INDEF múcura \\
\hline & & & & ‘Griselda me dio una múcura' \\
\hline & & & & jï-apaj-ï-in Griselda wanee amüchi ta-müin \\
\hline & & & & 3FEM.SG-dar-PAS-OD Griselda INDEF múcura 1SG-DAT \\
\hline & & & & 'Griselda me dio una múcura' \\
\hline & \multirow{4}{*}{\multicolumn{2}{|c|}{ Plural }} & Nos & wa-müin \\
\hline & & & Nos compras un auto lujoso. & jï-apaj-ï-in wa-müin Griselda wanee amüchi \\
\hline & & & & 3FEM.SG-dar-PAS-OD ISG-DAT Griselda INDEF múcura \\
\hline & & & & 'Griselda nos dio una múcura' \\
\hline \multirow[t]{8}{*}{ 2." persona } & \multirow{4}{*}{\multicolumn{2}{|c|}{ Singular }} & Te & pü-müin / pi-müin* \\
\hline & & & Te compraré un auto lujoso. & ¡̈̈-apaj-ï-in pü-müin Griselda wanee amüchi \\
\hline & & & & 3FEM.SG-dar-PAS-OD ISG-DAT Griselda INDEF múcura \\
\hline & & & & 'Griselda te dio una múcura' \\
\hline & \multirow{4}{*}{\multicolumn{2}{|c|}{ Plural }} & Os & jï-müin / ji-müin* \\
\hline & & & Os compraré un auto lujoso. & jï-apaj-ï-in j̈̈-müin Griselda wanee amüchi \\
\hline & & & & 3FEM.SG-dar-PAS-OD ISG-DAT Griselda INDEF múcura \\
\hline & & & & 'Griselda os dio una múcura' \\
\hline \multirow[t]{16}{*}{ 3. persona } & \multirow{8}{*}{$\begin{array}{l}\text { 흠 } \\
\text { 产 }\end{array}$} & \multirow[t]{3}{*}{ Masc. } & Le & nü-müin / ni-müin* \\
\hline & & & Le compraste un auto lujoso. & jï-apaj-ï-in nü-müin Griselda wanee amüchi \\
\hline & & & Se & 3FEM.SG-dar-PAS-OD ISG-DAT Griselda INDEF múcura \\
\hline & & \multirow{5}{*}{ Fem. } & Se lo compraste. & ‘Griselda le dio una múcura’ (a él) \\
\hline & & & & jï-müin / ji-müin* \\
\hline & & & & jï-apaj-ï-in jü-müin Griselda wanee amüchi \\
\hline & & & & 3FEM.SG-dar-PAS-OD 1SG-DAT Griselda INDEF múcura \\
\hline & & & & ‘Griselda le dio una múcura' (a ella) \\
\hline & \multirow{8}{*}{ 홈 } & \multirow[t]{3}{*}{ Masculino } & Les & na-müin \\
\hline & & & Les comprarás un auto & jï-apaj-ï-in na-müin Griselda wanee amüchi \\
\hline & & & lujoso. & 3FEM.SG-dar-PAS-OD ISG-DAT Griselda INDEF múcura \\
\hline & & \multirow{5}{*}{ Femenino } & Se & ‘Griselda les dio una múcura’ (a ellos) \\
\hline & & & Se los comprarás. & jia-irua-müin \\
\hline & & & (cuando el pronombre de & jï-apaj-ï-in jia-irua-müin Griselda wanee amüchi \\
\hline & & & acusativo presenta rasgos de & 3FEM.SG-dar-PAS-OD 1SG-DAT Griselda INDEF múcura \\
\hline & & & tercera persona) & ‘Griselda les dio una múcura’ (a ellas) \\
\hline
\end{tabular}

*De acuerdo con Ramírez y Dieck (2019), "la variación entre jü- / ji-, nü- / ni-y pü-/pi-probablemente esté relacionada con la armonía vocálica. Sin embargo, por el momento, con los datos existentes, no se pueden postular regularidades concluyentes" (p. 495).

Fuente: Los ejemplos mostrados en esta tabla fueron tomados o adaptados del artículo "Los pronombres personales en wayuunaiki” (Ramírez y Dieck, 2019, pp. 501-502). 
también fungen como objeto indirecto, como se ilustra en el Ejemplo 7.

Ejemplo 7:

Les traeré un regalo a ustedes.

\section{Discusión}

El presente trabajo constituye el primer esfuerzo por comparar los sistemas pronominales del español y el wayuunaiki. Este análisis pone de relieve que existen importantes diferencias entre ambas lenguas y algunos puntos de similitud. Sin embargo, debe tenerse en cuenta que este no es un estudio exhaustivo sobre el tema, pues para ello serán necesarias más investigaciones que permitan establecer si en wayuunaiki existen restricciones sociolingüísticas que determinen la preferencia en el uso de sujetos expresos, nulos y libres o ligados, como se han identificado en la lengua española (véase, por ej. Carvalho et al., 2015).

Como pudo evidenciarse, los pronombres personales en español y en wayuunaiki tienen algunas semejanzas que facilitan su estudio y, por tanto, el aprendizaje de estas lenguas como L2. En primer lugar, ambas permiten la expresión nula de los pronombres de sujeto, lo que significa que se clasifican como lenguas Pro-Drop. Por dicha razón, estas lenguas poseen también una variedad de marcas que, ligadas al verbo, explicitan el sujeto al que se refiere la oración. Otra semejanza consiste en que los pronombres personales de sujeto libres pueden constituir por sí solos un enunciado y, además, estos no establecen diferencias de género para la primera y la segunda persona singular, mientras que sí lo hacen para la tercera tanto de singular como de plural. Lo anterior resulta lógico al tener en cuenta que la tercera persona no está presente en muchos casos en cada situación comunicativa y, por ello, es necesario precisar su género. En relación con los pronombres de objeto directo y de objeto indirecto, no se encuentran semejanzas.

En lo relacionado con las diferencias, una de ellas se evidencia en la posición que ocupan los pronombres personales de sujeto y de objeto directo al interior de la oración. En español, estos últimos pueden aparecer en posición proclítica o enclítica; en wayuunaiki, por lo general, aparecen posterior al verbo, pero no ligados a este. En cuanto a los pronombres personales de sujeto, estos, en español, ocupan la posición que precede al verbo, mientras que, en wayuunaiki, ocupan la posición posterior al verbo.

Estos pronombres de sujeto también se diferencian en la forma utilizada para marcar el género y el número, pues en español no varían de acuerdo con el tiempo del verbo; en cambio, en wayuunaiki, sí se presenta dicha variación. Otra diferencia importante en los pronombres de objeto directo es que, en español, pueden ser de dos tipos: átonos o tónicos; por su parte, en wayuunaiki, solo tienen una forma. Los pronombres personales de objeto indirecto se diferencian, dado que en wayuunaiki se utiliza la marca - müin, ligada a la marca de persona y, en español, estos pronombres tienen las mismas formas que los de objeto directo para la primera y la segunda persona, y solo se diferencian de ellos por el contexto oracional o situacional.

Dados los contrastes identificados en el presente trabajo, es posible realizar algunas predicciones que deben ser puestas a prueba en estudios de contacto de lenguas y adquisición de L2. Lo anterior cobra importancia a raíz del fuerte contacto que estos idiomas tienen en el Caribe colombiano y venezolano, así como por el interés existente en fomentar una educación bilingüe en la misma región.

En primer lugar, debido a las similitudes entre las configuraciones de los sistemas pronominales de sujeto en el español y el wayuunaiki, y a su fácil identificación como referentes, es de esperarse que, para los aprendices de ambas lenguas como L2, se facilite la adquisición de estos. Por el contrario, se espera que, debido a las diferencias entre los sistemas pronominales de objeto directo e indirecto, y a su menor prominencia en las oraciones, estos sean adquiridos posteriormente. De igual modo, resulta probable que, debido a las 
diferencias de estos últimos, algunas de sus características (p. ej., como la marcación de género o de número) puedan ser transferidas de la L1 a la L2. En este sentido, también se espera que los aprendices de wayuunaiki como L2 tiendan a omitir las partículas de género en las oraciones en las que empleen un sujeto expreso. Esto, debido a que en español no ocurre tal diferencia.

Dadas las distintas configuraciones en el orden oracional de los dos sistemas lingüísticos, se espera que los wayuu aprendices del español como L2 tiendan a usar más sujetos postverbales que los hablantes nativos de la lengua romance. Contrario a ello, para quienes estén mucho más inmersos en el uso del español, se espera que tiendan a trasladar el orden sujeto + verbo + objeto al wayuunaiki. Lo mismo puede suceder con los hablantes nativos de español que están aprendiendo el wayuunaiki.

Por otro lado, es de suponerse que, debido a que los pronombres de objeto indirecto son marcados con -müin en wayuunaiki, estos pueden ser notables para los aprendices de este como L2. Contrario a ello, como en español se usan pronombres tónicos y átonos, lo más probable es que su adquisición por parte de los wayuu sea divergente a la de los hablantes nativos, y que, por tanto, se concentre en uno de los dos, por su carácter menos marcado.

A su vez, el hecho de que ambas lenguas sean de sujeto nulo puede sugerir que, al igual que en otras situaciones de contacto entre sistemas lingüísticos de este tipo (p. ej. veneto en contacto con el español, Barnes, 2010; maya en contacto con español, Michnowicz, 2015; español en contacto con wayuunaiki, Méndez, 2014; inter alia), los porcentajes de sujetos expresos se incrementen y, en algunos casos, las restricciones de tipo discursivo se debiliten. Lo anterior despierta aún más el interés si tenemos en cuenta que ambas comparten espacio en una zona en la cual el español se caracteriza por un alto porcentaje de uso de sujetos expresos en comparación con otras variedades del español (véase, por ej., Carvalho et al., 2015).
No se puede desconocer tampoco que, debido a las repercusiones del intenso contacto lingüístico y al efecto que este puede tener en los sistemas de cada lengua (Matras, 2009), además de la situación de bilingüismo prolongado en algunas zonas del norte colombiano y venezolano, es de esperarse que a nivel dialectal se pueda encontrar un continuum. Este puede mostrar diferencias con las variedades del wayuunaiki y del español, en la medida en la que el contacto y el bilingüismo se hagan más o menos intensos.

Todas las anteriores predicciones precisan ser puestas a prueba pronto; de allí la utilidad de este estudio contrastivo y de otros que puedan aportar luz sobre el tema. En este sentido, nos encontramos aún en una etapa inicial para el estudio lingüístico en la zona guajira.

\section{Conclusiones}

De acuerdo con lo visto, en el español y el wayuunaiki, los pronombres personales que cumplen funciones pronominales de sujeto, de objeto directo y de objeto indirecto tienen diferencias importantes. La posición que ocupan en la estructura oracional, las marcas utilizadas cuando no se expresa explícitamente el pronombre de sujeto y la estructura morfológica son quizás los elementos en donde se centran mayoritariamente las divergencias. Sin embargo, también tienen aspectos en común, como el hecho de que ambas lenguas pueden hacer uso de sujetos nulos y que los pronombres personales de sujeto libres no establecen diferencias de género para la primera y la segunda persona, mientras que sí lo hacen para la tercera.

Dada la utilidad de este tipo de trabajos para el aprendizaje de lenguas y los estudios de traducción (Ramón García, 2001; Rienda y Nieto, 2018; Tricás Preckler, 2010), resulta entonces valioso tener presente todos los elementos aquí desarrollados. Se hace necesario que los creadores de materiales didácticos para la enseñanza de ambas lenguas tengan en cuenta este tipo de estudios y que las actividades propuestas busquen fortalecer 
las zonas en las que ambos sistemas gramaticales divergen. De igual manera, quienes se ocupan de la traducción wayuunaiki-español, pueden hacer uso de este tipo de investigaciones para facilitar su labor.

Por su parte, los estudios de bilingüismo y contacto de lenguas necesitan partir desde los hallazgos e hipótesis vistas en este estudio, y otros que le sigan, para dar cuenta de las particularidades que dicho contacto y bilingüismo poseen. Esto, sin duda, aportará a la teoría lingüística. Como efecto paralelo, se espera que el presente análisis pueda contribuir al aprendizaje y a la valoración de la lengua indígena, además de la importancia que se le debe dar al bilingüismo y a la diversidad cultural.

Por último, es fundamental señalar que no se hizo alusión a dos formas de pronombres personales: pronombres posesivos y pronombres oblicuos. Estos, al igual que otras unidades gramaticales, esperan por investigaciones contrastivas. Es primordial resaltar que nos encontramos en un momento histórico que provee las herramientas y los conocimientos necesarios para adentrarnos en estudios de este tipo. El futuro del legado histórico y cultural del wayuunaiki y del bilingüismo guajiro dependen, en parte, de los esfuerzos que la comunidad científica pueda hacer por promoverlos en el presente.

\section{Referencias}

Aikhenvald, A. Y. (1999). The Arawak language family. En R. Dixon y A. Y. Aikhenvald (Eds.), The Amazonian languages (pp. 65-106). Cambridge University Press.

Alfaraz, G. (2015). Variation of overt and null subject pronouns in the Spanish of Santo Domingo. En A. M., Carvalho, R. Orozco y N. Lapidus Shin (Eds.), Subject pronoun expression in Spanish: A cross-dialectal perspective (pp. 3-16). Georgetown University Press.

Almela Pérez, R. (2015). Morfología flexiva del español. Diego Marín.

Álvarez,J. (2017). Compendio de la gramática de la lengua wayuu. https://www.academia.edu/35187896/Compendio_ de_la_gram\%C3\%A1tica_de_la_lengua_wayuu

Atencio, M. (2014). Rasgos distintivos del español en contacto con el wayuunaiki en la parroquia Andrés Bello del municipio La Cañada de Urdaneta del Estado Zulia, Venezuela [Unpublished master's dissertation]. University of Amsterdam.

Barnes, H. (2010). Subject pronoun expression in bilinguals of two null subject languages. En K. Arregui, Z. Fagyal, S. A. Montrul y A. Tremblay, Interactions in romance. Selected papers from the $38^{\text {th }}$ Linguistic Symposium on Romance Languages (LSRL) (pp. 9-22). John Benjamin Publishing Company.

Carvalho, A. M., Orozco, R. y Lapidus Shin N. L. (2015). Subject personal pronouns in Spanish. A cross-dialectalperspective. Georgetown University Press.

Civallero, E. (2008). Cultures ancestrals en universos moderns. Digithum, (10), 1-5. http://www.uoc.edu/ digithum/10/dt/esp/civallero.pdf

Creissels, D. (2006). Syntaxe générale. Une introduction typologique 1 Catégories et constructions. Lavoisier.

De Carvalho, F. (2016). The diachrony of person-number marking in the Lokono-Wayuunaiki subgroup of the Arawak family: reconstruction, sound change and analogy. Language Sciences, (55), 1-15. https://doi. org/10.1016/j.langsci.2016.02.001

De La Rosa Yacomelo, J. (2020a). Sujetos nulos: tipología lingüística, adquisición y contacto de lenguas. Forma y Función, 33(2), 109-134. https://www.doi. org/10.15446/fyf.v33n2.79774

De La Rosa Yacomelo, J. (2020b). Subject pronoun expression in Spanish-Palenquero bilinguals: Contact and Second Language Acquisition [Tesis doctoral]. The Pennsylvania State University.

Ehrman, S. (1972). Wayuunaiki. A grammar of guajiro [Tesis doctoral inédita]. University of Columbia.

Ethnologue (s. f. 1). Spanish. https://www.ethnologue. com/language/spa

Ethnologue (s. f. 2). Wayuu. https://www.ethnologue.com/ language/guc

Etxebarria Arostegui, M. (2012). Bilingüismo y realidad sociolingüística de la lengua del grupo wayuu en el Caribe colombiano. Anuario del Seminario de Filología Vasca Julio de Urquijo International Journal of Basque Linguistics and Philology (ASJU), 46(2), 271-295. https://dialnet.unirioja.es/servlet/ articulo?codigo $=4922040$

Fernández-Ordoñez, I. (1994). Isoglosas internas del castellano. El sistema referencial del pronombre átono de tercera persona. Revista de Filología Española, 74(1/2),71-125. https://doi.org/10.3989/rfe.1994. v74.i1/2.499 
Fernández Soriano, O. (1999). El pronombre personal. Formas y distribuciones. Pronombres átonos y tónicos. En I. Bosque y V. Demonte (Eds.), Gramática descriptiva de la lengua española (pp. 1209-1273). Espasa.

Fontanella de Weinberg, M. B. (1999). Sistemas pronominales de tratamiento usados en el mundo hispánico. En I. Bosque y V. Demonte (Eds.), Gramática descriptiva de la lengua española (Vol. 1, pp. 1399-1426). Espasa Calpe S. A.

Gallardo, A. (2004). Pronombre personal y persona gramatical. Onomázein, 2(10), 93-102. https://www. redalyc.org/pdf/1345/134517755004.pdf

Holmquist, J. (2012). Frequency rates and constraints on subject personal pronoun expression: Findings from Puerto Rican highlands. Language Variation and Change, 24(2), 203-220. https://doi.org/10.1017/ S0954394512000117

Instituto Cervantes (2019). El español una lengua viva: Informe 2019. https://www.cervantes.es/imagenes/ File/espanol_lengua_viva_2019.pdf

Landaburu, J. (2004-2005). Las lenguas indígenas de Colombia: presentación y estado del arte. Amerindia, 30(29), 3-22. https://www.sedyl.cnrs.fr/amerindia/ articles/pdf/A_29-30_00.pdf

Mansen, R. y Captain, D. (2000). El idioma guajiro. En M. González y M. Rodríguez (Eds.), Lenguas indígenas de Colombia. Una visión descriptiva (pp. 795-810). Instituto Caro y Cuervo.

Matras, Y. (2009). Language contact. Cambridge University Press.

Martínez-Sanz, C. (2011). Null and overt subjects in a variable system: The case of Dominican Spanish [Doctoral dissertation]. University of Otawa.

Mejía Rodríguez, P.I. (2011). Situación sociolingüistica del wayuunaiki: Ranchería El Pasito [Tesis de maestría]. Universidad Nacional de Colombia.

Méndez Rivera, N. J. (2014). La expresión de los pronombres personales sujetos en español: evidencia desde el lenguaje nativo y no nativo y sus implicaciones para la clase de Español Lengua Extranjera. IX Conferencia Internacional sobre Lenguas Extranjeras, Comunicación y Cultura.

Méndez-Rivera, N. J. (2020). Linguistic outcomes of the Wayuunaiki-Spanish Language contact situation [Tesis doctoral]. University of Ottawa.

Michnowicz, J. (2015). Subject pronoun expression in contact with Maya in Yucatan Spanish. In A. M., Carvalho, R. Orozco y N. Lapidus Shin (Eds.), Subject pronoun expression in Spanish. A cross-dialectal perspective (pp. 101-119). Georgetown University Press.

Mijangos, V. y Ponce de León, R. Z. (2017). Tratamiento de la flexión verbal en español a partir del modelo de palabra y paradigma. Borealis: An International Journal of Hispanic Linguistics, 6(2), 207-231. http:// dx.doi.org/10.7557/1.6.2.4116

Moreno-Fernández, F., Penadés-Martínez, I. y Ureña-Tormo, C. (2020). Gramática fundamental del español. Routledge Taylor \& Francis Group.

Olza, J. y Jusayú, M. A. (2012). Gramática de la lengua guajira

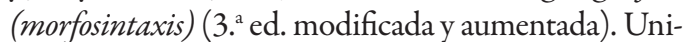
versidad Católica Andrés Bello, Montalbán La Vega.

Oquendo, L. (2014). Estrategias de desarrollo del español como segunda lengua para estudiantes indígenas universitarios. Lengua y Habla, (18), 107-117. https:// www.redalyc.org/pdf/5119/511951374008.pdf

Orozco, R. (2015). Pronominal variation in Colombian Costeño Spanish. In A. M., Carvalho, R. Orozco y N. Lapidus Shin (Eds.), Subject pronoun expression in Spanish. A cross-dialectal perspective (pp. 17-37). Georgetown University Press.

Otheguy, R. y Zentella, A. C. (2012). Spanish in New York. Language contact, dialectal leveling, and structural continuity. Oxford University Press.

Pérez van Leenden, F. (2003). Aproximaciones a la multi e interculturalidad y a la calidad y mediocridad educativa en La Guajira. En I Congreso Colombia inteligente: estándares y estrategias de aula para la formación de lectores competentes, Fonseca; Uniguajira / CELIKUD / SEEBI.

Pimiento Prieto, M. y Pérez van-Leeden F. J. (1997). La traducción de apartes de la Constitución Política de Colombia al wayuunaiki: algunos aspectos y problemas. Amerindia, (22), 151-176. https://sedyl.cnrs. fr/amerindia/articles/pdf/A_22_12.pdf

Ramírez, H. (2012). El español en territorios indígenas. En C. Patiño Roselli y J. Bernal Leongómez (Coords.), El lenguaje en Colombia (pp. 673-693). Academia Colombiana de la Lengua e Instituto Caro y Cuervo.

Ramírez, R. (2011). Interrelación sociolingüistica wayuu y criolla en la ciudad de Riohacha. Gente Nueva.

Ramírez, R. (2018). Categorías gramaticales relacionadas con el nombre en wayunaiki. [Tesis doctoral]. Universidad de Antioquia.

Ramírez González, R. y Dieck, M. (2019). Los pronombres personales en wayuunaiki. Lenguaje, 47(2), 479-513. https://doi.org/10.25100/lenguaje.v47i3.6824 
Ramírez González, R. y De La Rosa Yacomelo, J. (2021). La movilidad de los indígenas wayuu. Migración y contacto de lenguas [en proceso de publicación].

Ramón García, N. (2001). Lingüística contrastiva y traducción. En A. Barr, J. Torres del Rey y M. R. Martín Ruano (Eds.), Últimas corrientes teóricas en los estudios de traducción y sus aplicaciones (pp. $617-$ 623). Universidad de Salamanca.

Real Academia Española. (2019, 11 de noviembre de). Diccionario de la lengua española. https://dle.rae.es/ pronombre

Real Academia Española. (2010). Nueva gramática de la lengua española. Espasa Libros, S. L. U.

Rienda, J. y Nieto Núñez, N. M. (2018). Lingüística contrastiva y lenguas cognadas en el contexto del aula de ELE en Brasil. Porta Linguarum, (30), 103-115. https:// dialnet.unirioja.es/descarga/articulo/6691577.pdf

Sabogal Valencia, A. M. (2018). The variable expression of transitive subject and possessor in Wayuunaiki (Guajiro) [Tesis doctoral]. The University of New Mexico.

Salcedo, C. (2010). The phonological system of Spanish. Revista de Lingüistica y Lenguas Aplicadas, 5, 195209. https://doi.org/10.4995/rlyla.2010.769

Tricás Preckler, M. (2010). Lingüística contrastiva y traducción: aproximaciones interculturales, Synergies Espagne, (3), 13-22. https://dialnet.unirioja.es/ servlet/articulo codigo $=3194042$

Trillos Amaya, M. (2020). Los derechos linguísticos en Colombia: avances y desafíos. Lingüistica y Literatura, 41(77), 172-201. https://doi.org/10.17533/udea.lyl.n77a08

\section{Anexos}

\section{Anexo 1. Listado de materiales para la enseñanza del wayuunaiki}

Álvarez, J. (s. f.). Curso inicial de lengua wayuu. Lectoescritura y gramática básica. https://www.academia.edu/15288192/ Curso_inicial_de_lengua_wayuu_Lectoescritura_y_gram\%C3\%A1 tica_b\%C3\%A1sica

Apps YoGo. (2014). Traductor wayuunaiki (Versión 1.0) [Aplicación móvil]. Google Play Store. Riohacha, La Guajira, Colombia. https://play.google.com/store/apps/details?id=co.com.yogo.wayuunaiki\&hl=es\&gl=US

Bustos Flórez, Y. A. (2014). Waashajaai Wanüiki - Hablemos nuestra lengua. [Audiocurso. Incluye libro y CD. Autoedición].

Gonzalez, M. (2001). Wayuunkeera. Cartilla trilingüe \& cuaderno de actividades. https://es.scribd.com/doc/2626340/ Wayuunkeera-Manual-de-wayuu

Oñate Díaz, G. M. (2010). Cartilla de wayuunaiki. El guajirito lee y escribe. Universidad de La Guajira.

\section{Anexo 2. Listado de abreviaturas}

$1 S G=1 .{ }^{a}$ persona singular

$1 \mathrm{PL}=1 .^{\mathrm{a}}$ persona plural

$2 \mathrm{SG}=2 \cdot{ }^{\mathrm{a}}$ persona singular

$2 \mathrm{PL}=2 \cdot{ }^{\mathrm{a}}$ persona plural

3SG.MASC $=3 \cdot{ }^{\mathrm{a}}$ persona singular masculino

3PL.MASC $=3 .^{\mathrm{a}}$ persona plural masculino

3SG.FEM $=3{ }^{\mathrm{a}}$ persona singular femenino 
3PL.FEM $=3 .{ }^{a}$ persona plural femenino

$\mathrm{PL}=$ plural

PAS $=$ pasado

PRES $=$ presente

$\mathrm{FUT}=$ futuro

MASC.SG $=$ masculino singular

FEM.SG = femenino singular

GEN = genitivo

SUP $=$ superisivo*

$\mathrm{OD}=$ objeto directo

$\mathrm{DEF}=$ definido

INDEF $=$ indefinido

$\mathrm{DAT}=$ dativo

* Es una marca de caso típica de la lengua wayuu que se utiliza para indicar posición "encima de, sobre". El caso fue documentado en Ramírez (2018).

Cómo citar este artículo: Viloria Rodríguez, L., De La Rosa Yacomelo, J., Ramírez González, R., y García Segura, D. (2022). Pronombres en wayuunaiki y español: una mirada contrastiva. Íkala, Revista de Lenguaje y Cultura, 27(1), 153-173. https://doi.org/10.17533/udea.ikala.v27n1a08 